\title{
OPTICAL CHARACTER RECOGNITION METHOdS FOR NUMBER Plate Recognition: A Systematic Literature ReVieW
}

\author{
Andrea Gutai, Sara Havzi*, Darko Stefanovic, Andras Anderla \& Srdjan Sladojevic
}
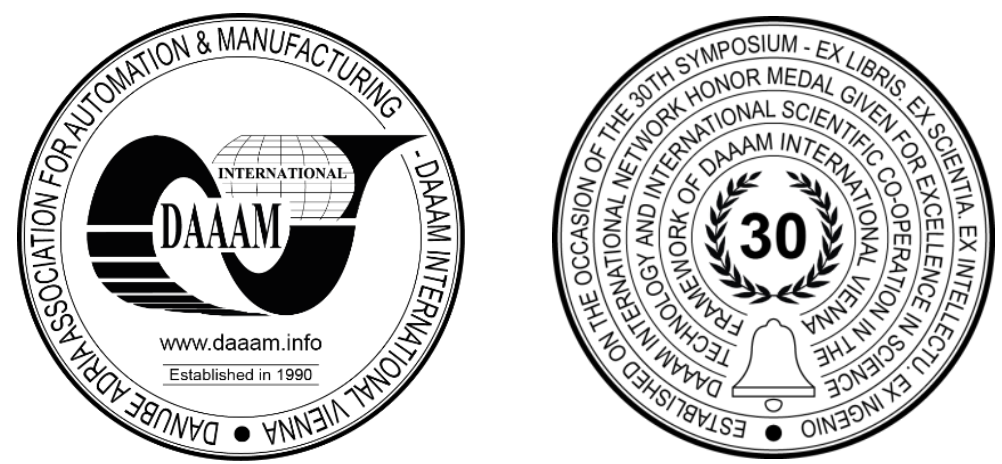

This Publication has to be referred as: Gutai, A[ndrea]; Havzi, S[ara]; Stefanovic, D[arko]; Anderla, A[ndras] \& Sladojevic, S[rdjan] (2021). Optical Character Recognition Methods For Number Plate Recognition: A Systematic Literature Review, Proceedings of the 32nd DAAAM International Symposium, pp.0692-0700, B. Katalinic (Ed.), Published by DAAAM International, ISBN 978-3-902734-33-4, ISSN 1726-9679, Vienna, Austria DOI: $10.2507 / 32$ nd.daaam.proceedings.097

\begin{abstract}
In the last decade, data processing of vehicle license plates became a common subject of research with numerous methodologies proposed to address the problem. The license plate recognition technology converts image data from a camera into a character format that can be further processed and manipulated in a database in a specific application area. The characters on license plates are often unambiguous in identifying vehicles that are facilitated by optical character recognition methods. The aim of this systematic literature review is to provide an overview of the most common methods used for optical character recognition in automated number plate recognition systems, as well as their level of recognition accuracy.
\end{abstract}

Keywords: Optical Character Recognition; Methods; Automated Number Plate Recognition; Systematic Literature Review;

\section{Introduction}

The need to extract and interpret certain information from images has been a key to the development of digital image processing in recent decades. As a result, a system that can provide the user with appropriate information based on a digital image, without the need for human intervention, is required. Adequate identification of vehicles based on image strongly depends on the number plate recognition that benefits security systems. In the field of security, the license number can be utilized as a unique identifier to aid the process. Not only can vehicles be recognized in security applications, but there are also a variety of methods for facial detection and recognition [1]. Object recognition in systems based on image processing methods is influenced by numerous factors including camera resolution, low visibility, and weather conditions [2]. The characters on license plates, which are easy to read by humans but not by machines, are used to identify vehicles in the majority of cases. Due to the variety of plate formats and no uniform outside illumination circumstances during image acquisition, this task is rather demanding [3]. Additionally, the plate recognition process is affected by a variety of colors, languages, and fonts that can be found on license plates [4]. The aim of this study is to present available methods for optical character recognition in automated number plate recognition systems by conducting a systematic literature review. 
The rest of the paper is organized as follows: Section 2 contains a theoretical foundation about number plate recognition and optical character recognition, Section 3 represents a methodology for systematic literature review with defined research questions and inclusion and exclusion criteria. Section 4 describes related discussion for achieved results that are presented in Section 3, subsection 3.3 through graphs and tables. Finally, Section 5 represents conclusions and limitations of the study as well as research directions.

\section{Background and Related Work}

The widespread integration of information technologies in the majority aspects of life, contributes to the development of needs for information systems and data processing of license plates, as well as focus of researchers to propose different methodologies to address the problem. The three primary phases of an automated number plate recognition (ANPR) system are license plate detection, segmentation and character recognition which is shown in Figure 1. The main purpose of number plate recognition systems is to extract the license plate completely automatically and recognize the characters, which are then written to a text file for data manipulation and storage. Converting image data from a camera into a character format that may be processed in a database for further manipulation in a specific application area is another objective of such systems. The input parameter is an image, while the output of the same process is a text file.

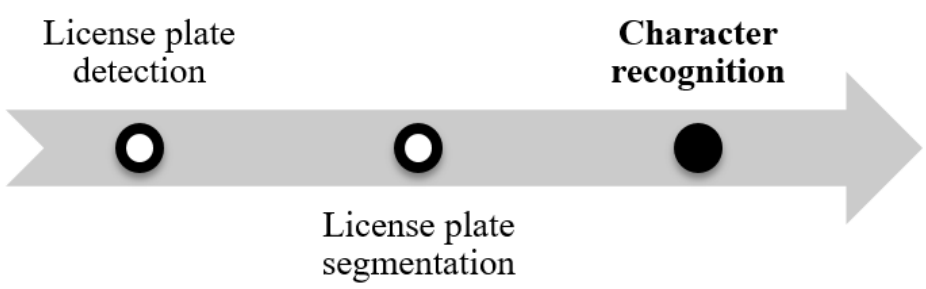

Fig. 1. Number plate recognition methodology

In order to obtain a text file numerous methods for character recognition step can be employed. Four general approaches of pattern recognition are: template matching, statistical techniques, structural techniques and artificial neural networks [5]. According to the specificity of licenses plates and field where these methods are supposed to be implemented, different modifications are required. Each license plate possesses a set of characters, letters and numbers, where an error in a single character leads to inaccurate recognition of the vehicle [6].

In order to achieve character recognition, three steps are required: segmentation, feature extraction and classification [5]. The character is recognized when it is assigned to a predetermined class or category. Different languages have an impact on the recognition process, because every methodology requires adjustments in order to recognize alphanumeric adequately, necessitating the adoption of methods for character recognition depending on the type of plate.

Each country has its own license plates with different font, letters, numbers and various other markings as well as shape and background colour of license plate. Creating a universal system for recognizing license plates would require enormous time resources, consequently researchers propose different methodologies focused on specific type of license plate in accordance with the regulations of the area.

Recognition accuracy represents a crucial parameter for the evaluation of proposed methods, which is calculated by the ratio of successfully recognized license plates to a total number of images used for method testing. Consequently, number of images used for the testing method is another parameter that should be considered while evaluating the method. Equation (1) is proposed by Yang et al. [7]

$$
\text { rate }=\left(1-\frac{\text { error }}{\text { total }}\right) \times 100 \%
$$

\section{Methodology}

This research is intended to represent the methods that are widely used for character recognition phase that is a vital part of automated number plate recognition process. Kitchenham B. established a guideline for systematic reviews [7], which was used to conduct the review.

\subsection{Planning the Review}

In order to gather necessary information about the need for a systematic literature review, a thorough review of previous work is required [8]. Consequently, no explicit systematic literature review summarizing optical character recognition methods in automated number plate recognition systems was found. An inevitable part of review is formulation of research questions, which are formulated as follows: 
RQ1: Which optical character recognition methods are most frequently used in ANPR?

RQ2: Which optical character recognition algorithms in ANPR have the highest rate of accuracy?

RQ3: Does the type of method used for optical character recognition affects recognition accuracy?

For the literature review, the following databases were used:

- Scopus and

- Web of Science.

Words, terms, and phrases used for automatic search in the aforementioned databases are stated as follows:

( "optical character recognition" OR "ocr")

AND

( "artifical neural networks" OR "ann" OR "kernel" OR "statistical method" OR "template matching" OR "structural pattern recognition" )

AND

( "automatic number plate recognition" OR "automated number plate

recognition" OR "anpr" OR "alpr" OR "number plate recognition" OR "npr" OR "vehicle plate

" OR "number plate" OR "license plate" OR "lpr" OR "car plate"))

$A N D$

PUBYEAR > 2009

Definition of inclusion and exclusion criteria facilitate the selection process of primary studies [8]. Only primary studies that are relevant to research questions will be taken into consideration.

Inclusion criteria is defined as follows:

IC1: Paper has to be written in English.

IC2: Paper has to present a study on ANPR with the rate of character recognition accuracy.

IC3: Paper has to include detailed information about the optical character recognition step in automated number plate recognition for the proposed method.

IC4: License plates used for the proposed method should include alphabet letters and numbers.

Exclusion criteria is defined as follows:

EC1: If a paper is focused only on license plate recognition without character recognition, the paper should be removed.

EC2: Duplicate papers found in different databases should be removed.

EC3: Non-availability of full text.

Data extraction is the next step, where we should state which information will be obtained from studies [8]. Extraction of required information for all primary studies will include:

1. Publication year and source type;

2. Method used for optical character recognition;

3. The rate of recognition accuracy; and

4. Number of images used for method testing.

\subsection{Conducting the Review}

The first activity of the review phase is to identify studies that will be included in the systematic literature review. The review methodology, based on the inclusion and exclusion criteria is utilized to identify publications that will be taken into consideration. Figure 2 illustrates the flow diagram of the systematic literature review procedure, that resulted in 42 selected primary studies.
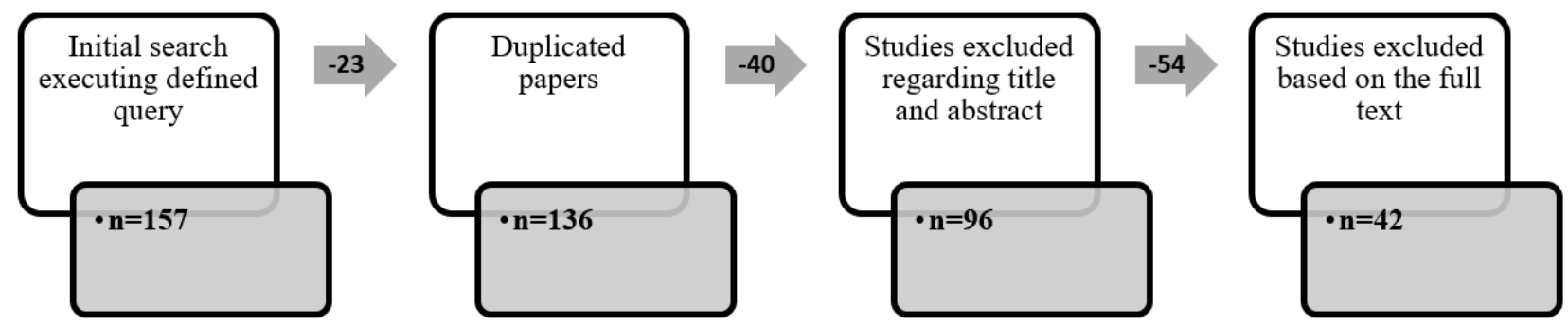

Fig. 2. Overview of the selection process 
The initial search in the databases for a previously determined query resulted in 157 publications. Due to the usage of two databases on the same query, several papers were duplicated, resulting in a total of 23 duplicated papers that were excluded. Based on the title and abstract of publications, 40 studies were excluded from further process. Inclusion and exclusion criteria were applied, resulting in the exclusion of 54 primary studies. Finally, a systematic literature review was conducted using a total of 42 publications.

\subsection{Data extraction and summarization}

In this chapter, previously selected primary studies (42) will be presented in form of tables and graphs that provide visual representation of extracted data. Depending on the source of publication, the majority of the publications, 33 publications $(79 \%)$ of a total of 42 were conference papers, while the remaining 9 publications $(21 \%)$ were articles, as presented in Table 1.

\begin{tabular}{|c|c|c|c|}
\hline Source Type & Primary studies & Number & \% \\
\hline & {$[9],[10],[11],[12],[13],[14],[15],[16],[17]$,} & & 79 \\
Conference paper & {$[18],[19],[20],[21],[22],[23],[24],[25]$,} \\
& $\begin{array}{c}26],[27],[28],[7],[29],[30],[31],[32],[33], \\
{[34],[35],[36],[37],[38],[39],[40]}\end{array}$ & 33 & \\
\hline Journal article & {$[41],[42],[43],[44],[45],[46],[47],[48]$,} & 9 & 21 \\
\hline
\end{tabular}

Table 1. Primary studies according to source type

The distribution of number of studies over the period from 2010 to 2020 is presented in Table 2. In the period of the previous ten years, the number of papers was similar per year, while in 2019 there was an increase in the number of papers, which is shown in the line diagram. Line diagram shown in Figure 3 illustrates that there was a peak in the number of published papers in 2019. In 2019, nine papers were published, compared to three to four papers each year on average per previous years.

\begin{tabular}{|c|c|c|c|}
\hline Year & Primary studies & Number & \% \\
\hline 2010 & {$[39],[38],[37]$} & 3 & 7.14 \\
\hline 2011 & {$[48],[36],[40]$} & 3 & 7.14 \\
\hline 2012 & {$[35],[34],[33],[32]$} & 4 & 9.52 \\
\hline 2013 & {$[31],[30]$} & 2 & 4.76 \\
\hline 2014 & {$[47],[29],[7]$} & 3 & 7.14 \\
\hline 2015 & {$[28],[27],[26]$} & 3 & 7.14 \\
\hline 2016 & {$[25],[46],[45],[24]$} & 4 & 9.52 \\
\hline 2017 & {$[44],[23],[22],[21]$} & 4 & 9.52 \\
\hline 2018 & {$[20],[19],[18]$} & 3 & 7.14 \\
\hline 2019 & {$[17],[16],[15],[14],[13],[43],[42],[12],[49]$} & 9 & 21.43 \\
\hline 2020 & {$[11],[10],[41],[9]$} & 4 & 9.52 \\
\hline
\end{tabular}

Table 2. Distribution of primary studies in the last 10 years

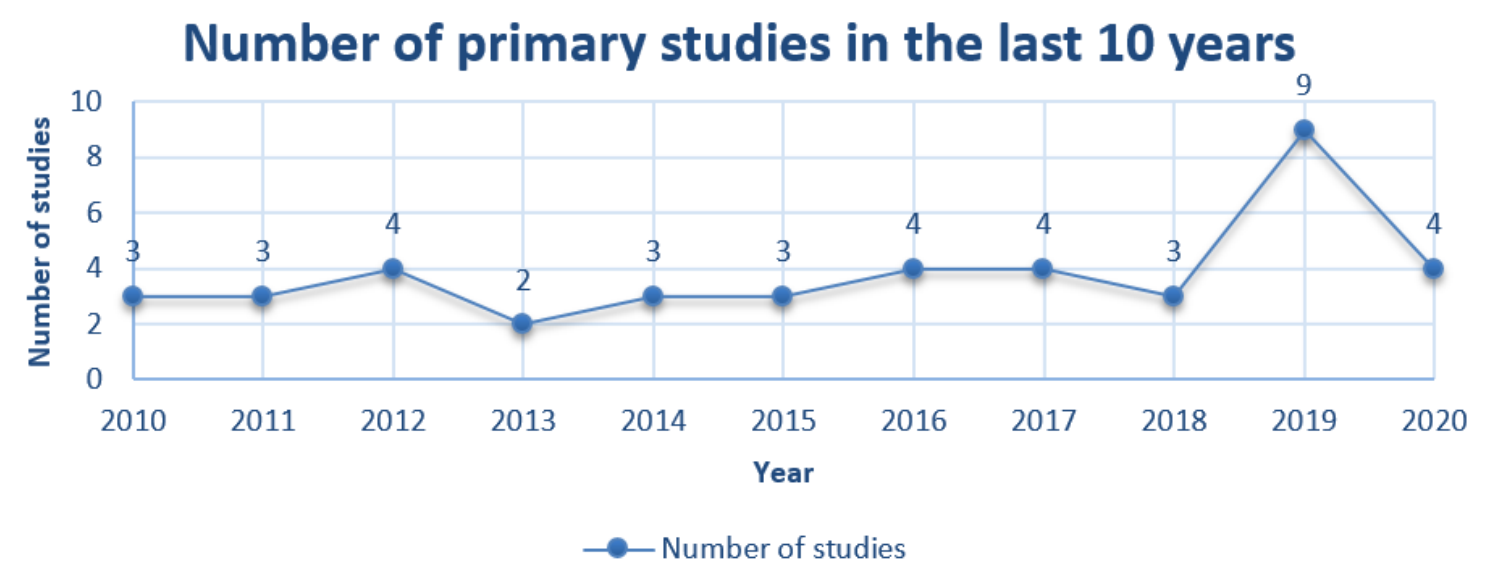

Fig. 3. Number of primary studies per year 
The papers were distributed according to the type of method used for the optical character recognition step in number plate recognition systems. Table 3 provides the response to the first research question. The template matching approach was employed in up to $55 \%$ of the articles, followed by a set of neural network methods that represents $38 \%$, Support Vector Machine (SVM) method in two studies (5\%), and finally K-Nearest Neighbours Algorithm (k-NN) method in only one study $(2 \%)$.

\begin{tabular}{|c|c|c|c|c|}
\hline & Method & Studies & Number & $\%$ \\
\hline \multicolumn{2}{|r|}{ Template Matching (TM) } & $\begin{array}{c}41],[10],[42],[14],[15],[16],[19], \\
{[20],[23],[24],[46],[25],[27],[28],[7],}\end{array}$ & 23 & 55 \\
\hline \multirow{5}{*}{$\begin{array}{l}\text { Neural } \\
\text { Networks }\end{array}$} & $\begin{array}{c}\text { Convolutional Neural } \\
\text { Network (CNN) }\end{array}$ & [9], [13], [17], [49] & 4 & \multirow{5}{*}{38} \\
\hline & $\begin{array}{c}\text { Deep Convolutional Network } \\
\text { (Deep CN) }\end{array}$ & [43] & 1 & \\
\hline & $\begin{array}{l}\text { Artificial Neural Network } \\
\text { (ANN) }\end{array}$ & {$[18],[22],[44],[26],[32],[34],[36],[39]$} & 8 & \\
\hline & $\begin{array}{l}\text { Extreme Learning Machine } \\
(\text { ELM) }\end{array}$ & [29] & 1 & \\
\hline & $\begin{array}{c}\text { Back Propagation (BP) Neural } \\
\text { Network }\end{array}$ & [47], [45] & 2 & \\
\hline \multicolumn{2}{|c|}{ Support Vector Machine (SVM) } & [11], [12] & 2 & 5 \\
\hline \multicolumn{2}{|c|}{ K-Nearest Neighbors Algorithm (k-NN) } & [21] & 1 & 2 \\
\hline
\end{tabular}

Table 3. Frequency of usage methods for OCR

Set of neural networks methods consists of five methods that are used for optical character recognition and their percentage share is shown in Figure 4. Artificial neural networks (ANNs) are the most widely used method in the group of neural networks, $50 \%$ of the total number of papers are related to neural networks ( 8 out of 16), followed by Convolutional neural networks $(\mathrm{CNN})$ which occupy $25 \%$ that is 4 publications out of 16. Back Propagation Neural Network is employed in two publications (13\%), while the remaining percentages are evenly distributed because the remaining methods, Deep Convolutional Network and Extreme Learning Machine had been proposed in one paper each.

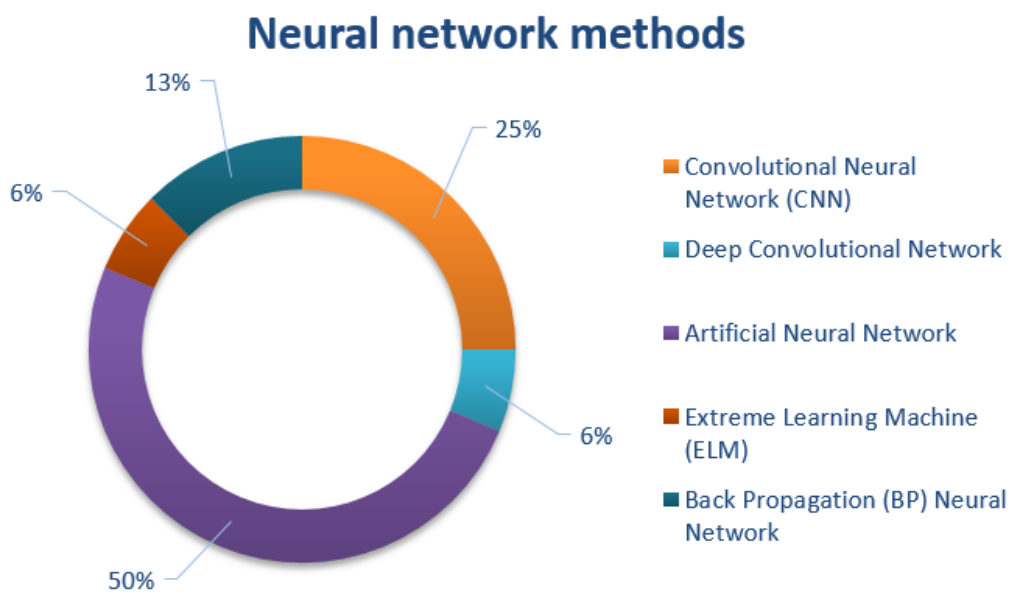

Fig. 4. Percentage share of five identified group of Neural network methods

The rate of recognition is another important aspect of evaluating proposed approaches, as well as number of images used for testing the method, which are shown in Table 4. The overall recognition rate is reported in the majority of articles $(81 \%)$. Researchers have provided rates for each step of localization, segmentation, and recognition in 11 articles $(26 \%)$. In 6 publications (14\%) researchers have stated two out of three rates. Overall recognition rate was the highest while using set of neural network methods. The highest overall recognition rate is shown in [17], where CNN method was used. Approaches that used deep convolutional networks [43] stated high recognition accuracy as well as in [9] where CNN method was used. Subsequently, two approaches that stated similar overall recognition rate were approaches [31] and [30] that used template matching technique. The highest rates for localization step is shown in template matching approach suggested by Pun et al. [48], for segmentation step the highest rate was achieved with template matching approach in [40], and finally the highest character recognition step had the highest percentage in again template matching approach suggested by [31]. 
The number of images used to test the method also contributes to a better understanding of the success rate of the method. In $83 \%$ of publications, researchers have stated the number of images used for testing their methodology. The highest number of image dataset used for method test was, undoubtedly, in convolutional neural network methods [13], [17] and [49] where number of images range from 4800 to 9000 images.

\begin{tabular}{|c|c|c|c|c|c|c|}
\hline $\begin{array}{l}\text { Primary } \\
\text { study }\end{array}$ & Method & $\begin{array}{c}\text { Localization } \\
\text { Rate }\end{array}$ & $\begin{array}{c}\text { Segmentation } \\
\text { Rate }\end{array}$ & $\begin{array}{c}\text { Recognition } \\
\text { Rate }\end{array}$ & $\begin{array}{c}\text { Overall } \\
\text { Recognition } \\
\text { Rate }(\%) \\
\end{array}$ & $\begin{array}{l}\text { Image } \\
\text { dataset }\end{array}$ \\
\hline [41] & $\mathrm{TM}$ & 96.5 & 95.6 & 94.4 & & 400 \\
\hline [10] & TM & & 96 & 98 & & 30 \\
\hline [42] & TM & 95 & 95 & 95 & 95 & 22 \\
\hline [14] & TM & & & & 82.5 & 40 \\
\hline [15] & TM & 97 & 97 & 98 & 92 & 100 \\
\hline [16] & TM & 94.66 & 96.45 & 95.41 & & 100 \\
\hline [19] & TM & & & & 82.6 & 3 \\
\hline [20] & TM & & & & 95 & 357 \\
\hline [23] & TM & 93.33 & 86.67 & 93.33 & & 45 \\
\hline$[24]$ & TM & 78.1 & 96 & 95 & 78.1 & 500 \\
\hline [46] & TM & & & & 85.87 & 80 \\
\hline [25] & TM & & & & 88.67 & 165 \\
\hline [27] & TM & & & & 92.78 & 100 \\
\hline [28] & TM & 89.13 & 95.12 & 97.94 & & 230 \\
\hline [7] & TM & & & & 96.08 & 1462 \\
\hline [30] & TM & & & & 97.46 & 30 \\
\hline [31] & TM & 97.5 & 97.71 & 100 & 98.73 & 80 \\
\hline [33] & TM & & & & 87.96 & \\
\hline [35] & TM & 94.11 & & 90.62 & 89.7 & 102 \\
\hline [48] & TM & 100 & & 95 & 95 & 100 \\
\hline [37] & TM & 85 & 90 & 91.66 & & 60 \\
\hline$[38]$ & TM & & & & 92.8 & 500 \\
\hline [40] & TM & 98.2 & 98.5 & 96.8 & & 288 \\
\hline [9] & $\mathrm{CNN}$ & & & & 98.73 & \\
\hline [13] & $\mathrm{CNN}$ & & & & 90 & 5000 \\
\hline [17] & $\mathrm{CNN}$ & & & & 99.98 & 9997 \\
\hline [49] & CNN & 91 & & 93 & 92 & 4800 \\
\hline [43] & Deep CN & & & & 99.32 & \\
\hline$[18]$ & ANN & 92 & 92 & 87 & 89.5 & 100 \\
\hline [22] & ANN & & & & 94.32 & 13 \\
\hline [44] & ANN & & & & 61 & 30 \\
\hline [26] & ANN & & & & 97 & 200 \\
\hline [32] & ANN & & & & 97.3 & \\
\hline [34] & ANN & & 83.5 & 92 & 88 & \\
\hline [36] & ANN & & & & 91.59 & 150 \\
\hline [39] & ANN & & & & 94.1 & \\
\hline [29] & ELM & 94.85 & & 97.9 & & 286 \\
\hline [47] & BP NN & & & & 91.2 & 1000 \\
\hline [45] & BP NN & & & & 70 & 80 \\
\hline [11] & SMV & & & & 95 & \\
\hline [12] & SMV & & & & 92.6 & 130 \\
\hline [21] & k-NN & & & & 87.43 & 30 \\
\hline
\end{tabular}

Table 4. Recognition accuracy rate and number of images used for testing

A one-way ANOVA was conducted to compare the effect of different methods on overall recognition accuracy stated in Table 4. The dependent variable was overall recognition accuracy, while the independent variable represented different methods used for optical character recognition. According to the null hypothesis, all population means are equal. The pvalue $(0.383)$ is greater than the significance level $(0.05)$, which leads to the conclusion that there is no enough evidence to reject the null hypothesis and that there are no statistically significant differences between the means. 


\section{Discussion}

The findings of the literature review reported in the previous data extraction and summarization will be discussed in this chapter. The number of publications over the years was approximate, except in 2019, there was an increase in the number of articles published, and it is expected that the number of publications will continue to increase. Looking at previous years, methodologies regarding automated number plate recognition have gained attention due to employment in a variety of fields, such as parking surveillance, toll collecting, different access control systems where license plates are stored in databases for further manipulation.

The most frequently used method for optical character recognition step in automated number plate recognition systems, in 23 publications out of 42 included in review are based on template matching technique. Followed by subcategory of neural network methods, artificial neural networks that are employed in 8 publications. The first research question (RQ1) is answered in this way. Overall recognition rate was highest while using set of neural network methods, convolution neural networks (CNNs). The highest overall recognition rate is shown in [17], where CNN method was used, additionally highest number of images was used to test the method. This provides an answer to the second research question (RQ2). The results of the ANOVA reveal that there is no statistically significant difference between the methods. ANOVA results gives a response to the third research question (RQ3).

The main limitation of this research is that every researcher has its own way of stating rate of accuracy, where majority of researchers have stated overall recognition accuracy. Hidayatullah et al. [46] used Likert scale to classify rate of recognition ranging from $0 \%$ to $100 \%$. Regarding Likert scale majority of publications included in systematic literature review could be classified as excellent, considering that they have a percentage range higher than 81 . Only three publications [24], [22] and [45] can be stated as good due to the belonging to the range from 60 to $81 \%$.

Another limitation is that methodologies were not tested on the same images, researchers used their own dataset and based on that they presented the success rates of the methodology. The use of an identical dataset would make it easier to compare all these methods. Thakur et al. [26] state that their methodology cannot be compared to other approaches regarding the same issue due to unavailability of set of images used to test the approach. Arafat et al. [41] used public datasets that consists of 126 additional images, besides their own dataset (400 images), to assess their own performance against other methodologies. This methodology could be taken in consideration as provable, while other methodologies could not be verified due to the unavailability of their datasets.

\section{Conclusion}

This study presented a review of optical character recognition methods in ANPR systems that have been proposed in numerous publications. The importance of the license plate recognition system, especially optical character recognition methods is affected by the need to reduce the human factor in this process, achieving a higher level of vehicle access control in a specific area, parking billing solutions, and automatic calculation of the time and money required to use the certain services. The most frequently used method for optical character recognition step is template matching technique. In state-of-the-art techniques, Convolutional Neural Network based recognition algorithms provide higher recognition rates comparing to traditional Template Matching technique, due to publications that we took into consideration. Due to the limitations stated in the discussion, if the image dataset is not available, it is hard to compare and evaluate proposed methods. Public datasets could be optimal solution for aforementioned limitation, and if future researchers would use public images, it would make methods suitable for comparison and verification. Further research should include stating accuracy rate for every step as well as, stating overall recognition accuracy should increase traceability and verifiability of specific methodology.

\section{References}

[1] Kotkova, B[arbora]; Hromada, M[artin]; Mach, V[aclav] \& Blahova, M[arta] (2019). Detection and Face Recognition of People by Camera for Security Applications, Proceedings of the 30th DAAAM International Symposium, pp.0610-0614, B. Katalinic (Ed.), Published by DAAAM International, ISBN 978-3-902734-22-8, ISSN 1726-9679, Vienna, Austria DOI: 10.2507/30th.daaam.proceedings.083

[2] Mach, V[aclav]; Kotkova, B[arbora] \& Hromada, M[artin] (2019). Detection and Recognition of People by Camera - Reliability and Use, Chapter 18 in DAAAM International Scientific Book 2019, pp.233-240, B. Katalinic (Ed.), Published by DAAAM International, ISBN 978-3-902734-24-2, ISSN 1726-9687, Vienna, Austria DOI: 10.2507/daaam.scibook.2019.18

[3] Anagnostopoulos, C. N. E.; Anagnostopoulos, I. E.; Psoroulas, I. D.; Loumos, V. \& Kayafas, E. (2008) "License plate recognition from still images and video sequences: A survey," IEEE Transactions on Intelligent Transportation Systems, vol. 9, no. 3, pp. 377-391, doi: 10.1109/TITS.2008.922938.

[4] Du, S.; Ibrahim, M.; Shehata, M. \& Badawy, W. (2013) "Automatic License Plate Recognition (ALPR): A Stateof-the-Art Review," IEEE Transactions on Circuits and Systems for Video Technology, vol. 23, no. 2, pp. 311325, doi: 10.1109/TCSVT.2012.2203741.

[5] Chaudhuri, A.; Mandaviya, K.; Badelia, P. \& Ghosh, S. K. (2017) "Optical Character Recognition Systems for Different Languages with Soft Computing,” Springer, ISBN 978-3-319-50251-9 
[6] A. Farhat et al. (2018) "Optical character recognition on heterogeneous SoC for HD automatic number plate recognition system," Eurasip Journal on Image and Video Processing, vol. 2018, no. 1, doi: 10.1186/s13640-0180298-2.

[7] Yang, X.; Zhao, Y.; Fang, J.; Lu, Y.; Zhang, Y. \& Yuan, Y. (2014) “A license plate segmentation algorithm based on mser and template matching," 12th International Conference on Signal Processing (ICSP), pp. 1195-1199, doi: 10.1109/ICOSP.2014.7015189.

[8] Kitchenham, B. (2004) Procedures for Performing Systematic Reviews, Keele University.

[9] Cai, Y.; Lin, X.; Qian, H. \& Lu, P. (2020) "FPGA Accelerator Design for License Plate Recognition Based on 1BIT Convolutional Neural Network," Journal of Physics: Conference Series, vol. 1621, doi: 10.1088/1742$6596 / 1621 / 1 / 012022$.

[10] Vaishnav, A. \& Mandot, M. (2020) "Template Matching for Automatic Number Plate Recognition System with Optical Character Recognition,” Advances in Intelligent Systems and Computing, vol. 933, Springer Verlag, pp. 683-694. doi: 10.1007/978-981-13-7166-0_69.

[11] Ding, H. \& Shen, J. (2020) "Research on license plate recognition of Chinese vehicle based on GWO-SVM algorithm," in WCSE 2020: 2020 10th International Workshop on Computer Science and Engineering, pp. 132137. doi: $10.18178 /$ wcse.2020.06.022.

[12] Pingping, L. \& Wenjing, X. (2019) "Research on Recognition Technology of License Plate Image," Proceedings 2nd International Conference on Computer Network, Electronic and Automation, ICCNEA, pp. 52-56. doi: 10.1109/ICCNEA.2019.00020.

[13] Suvarnam, B. \& Ch, V. S. (2019) "Combination of CNN-GRU Model to Recognize Characters of a License Plate number without Segmentation," 2019 5th International Conference on Advanced Computing \& Communication Systems (ICACCS), pp. 317-322. doi: 10.1109/ICACCS.2019.8728509.

[14] Brillantes, A. K. M.; Bandala, A. A.; Dadios, E. P. \& Jose, J. A. (2019) "Detection of Fonts and Characters with Hybrid Graphic-Text Plate Numbers," IEEE Region 10 Annual International Conference, Proceedings/TENCON, Feb. 2019, vol. 2018-October, pp. 629-633. doi: 10.1109/TENCON.2018.8650097.

[15] Chai, D. \& Zuo, Y. (2019) "Extraction, segmentation and recognition of vehicle's license plate numbers," Advances in Intelligent Systems and Computing, vol. 887, pp. 724-732. doi: 10.1007/978-3-030-03405-4_52.

[16] Indira, K.; Mohan, K. V. \& Nikhilashwary, T. (2019) “Automatic license plate recognition,” Advances in Intelligent Systems and Computing, vol. 727, pp. 67-77. doi: 10.1007/978-981-10-8863-6_8.

[17] Fu, M.; Chen, N.; Hou, X.; Sun, H.; Abdussalam, A. \& Sun, S. (2019) "Real-time vehicle license plate recognition using deep learning," Lecture Notes in Electrical Engineering, vol. 494, pp. 35-41. doi: 10.1007/978-981-13-1733$0 \_5$.

[18] Jagtap, J. \& Holambe, S. (2018) "Multi-Style License Plate Recognition usingArtificial Neural Network for Indian Vehicles," 2018 International Conference on Information, Communication, Engineering and Technology (ICICET), pp. 1-4. doi: 10.1109/ICICET.2018.8533707.

[19] Kashyap, A.; Suresh, B.; Patil, A.; Sharma, S. \& Jaiswal, A. (2018) "Automatic Number Plate Recognition," Proceedings - IEEE 2018 International Conference on Advances in Computing, Communication Control and Networking, ICACCCN 2018, Oct. 2018, pp. 838-843. doi: 10.1109/ICACCCN.2018.8748287.

[20] Jiang, Z.; Lin, Z.; Tang, J.; Li, H. \& Menglu, Y. (2018) "The fast recognition of vehicle license plate based on the improved template matching,” MATEC Web of Conferences, vol. 176. doi: 10.1051/matecconf/201817601029.

[21] Quiros, A. R. F.; Bedruz, R. A.; Uy, A. C.; Abad, A.; Bandala, A.; Dadios, E. P. \& Fernando, A. (2017) “A kNNbased Approach for the Machine Vision of Character Recognition of License Plate Numbers," TENCON 2017-2017 IEEE Region 10 Conference. IEEE, p. 1081-1086. doi: 10.1109/TENCON.2017.8228018.

[22] Alyahya, H. M.; Alharthi, M. K.; Alattas, A. M. \& Thayananthan, V. (2017) "Saudi License Plate Recognition System Using Artificial Neural Network Classifier," 2017 International Conference on Computer and Applications, ICCA 2017, Oct. 2017, pp. 220-226. doi: 10.1109/COMAPP.2017.8079759.

[23] Babu, K. M. \& Raghunadh, M. V. (2016) "Vehicle Number Plate Detection and Recognition using Bounding Box Method," International Conference on Advanced Communication Control and Computing Technologies (ICACCCT), pp. 106-110. doi: 10.1109/ICACCCT.2016.7831610.

[24] Saleem, N.; Muazzam, H.; Tahir, H. M. \& Farooq, U. (2016) “Automatic License Plate Recognition Using Extracted Features," 2016 4th international symposium on computational and business intelligence (ISCBI). IEEE, 2016. p. 221-225. doi: 10.1109/ISCBI.2016.7743288

[25] Choudhury, A. \& Negi, A. (2016) "A new zone based algorithm for detection of license plate from Indian vehicle," 2016 Fourth International Conference on Parallel, Distributed and Grid Computing (PDGC). IEEE, 2016. p. 370374. doi: 10.1109/PDGC.2016.7913178

[26] Thakur, M.; Raj, I. \& Ganesan, P. (2015) "The cooperative approach of genetic algorithm and neural network for the identification of vehicle license plate number," 2015 International Conference on Innovations in Information, Embedded and Communication Systems (ICIIECS). IEEE, 2015. p. 1-6. doi: 10.1109/ICIIECS.2015.7193090

[27] Jalil, N. A.; Basari, A. S. H.; Salam, S.; Ibrahim N. K. \& Norasikin, M. A. (2015) "The utilization of template matching method for license plate recognition: A case study in malaysia," Lecture Notes in Electrical Engineering, 2015, vol. 315, pp. 1081-1090. doi: 10.1007/978-3-319-07674-4_100. 
[28] Palai, C. \& Jena, P. K. (2015) "Automatic vehicle identification: LPR with enhanced noise removal technique," Smart Innovation, Systems and Technologies, 2015, vol. 31, pp. 143-153. doi: 10.1007/978-81-322-2205-7_14.

[29] Gou, C.; Wang, K.; Yu, Z. \& Xie, H. (2014) "License plate recognition using MSER and HOG based on ELM," Proceedings of 2014 IEEE International Conference on Service Operations and Logistics, and Informatics. IEEE, 2014. p. 217-221. doi: 10.1109/SOLI.2014.6960724

[30] Mutholib, A.; Gunawan, T. S.; Chebil, J. \& Kartiwi, M. (2013) “Optimization of ANPR algorithm on android mobile phone," 2013 IEEE International Conference on Smart Instrumentation, Measurement and Applications (ICSIMA). IEEE, 2013. p. 1-5. doi: 10.1109/ICSIMA.2013.6717950.

[31] Shaikh, S.; Lahiri, B.; Bhatt, G. \& Raja, N. (2013) "A novel approach for Automatic Number Plate Recognition," 2013 International Conference on Intelligent Systems and Signal Processing (ISSP). IEEE, p. 375-380. doi: 10.1109/ISSP.2013.6526938

[32] Zhai, X.; Bensaali, F. \& Sotudeh, R. (2012) “OCR-Based Neural Network for ANPR,” 2012 IEEE International Conference on Imaging Systems and Techniques Proceedings. IEEE, p. 393-397. doi: 10.1109/IST.2012.6295581

[33] Hidayatullah, P.; Syakrani, N.; Suhartini, I. \& Muhlis, W. (2012) "Optical character recognition improvement for license plate recognition in Indonesia," Proceedings - UKSim-AMSS 6th European Modelling Symposium, EMS 2012, pp. 249-254. doi: 10.1109/EMS.2012.95.

[34] Mutholib, A.; Gunawan, T. S. \& Kartiwi, M. (2012) "Design and Implementation of Automatic Number Plate Recognition on Android Platform," 2012 International Conference on Computer and Communication Engineering (ICCCE). IEEE, 2012. p. 540-543. doi: 10.1109/ICCCE.2012.6271245

[35] Rasheed, S.; Naeem, A. \& Ishaq, O. (2012) "Automated Number Plate Recognition Using Hough Lines and Template Matching," Proceedings of the world congress on engineering and computer science. 2012. p. 24-26.

[36] Roy, A., \& Ghoshal, D. P. (2011) "Number Plate Recognition for Use in Different Countries Using an Improved Segmentation," 2011 2nd National Conference on Emerging Trends and Applications in Computer Science. IEEE, 2011. p. 1-5. doi: 10.1109/NCETACS.2011.5751407

[37] Ahmad, W.; Hassan, S. A.; Irfan, M. A.; Bais, A.; Hassan, G. M.; Shah, S. A. A. \& Yahya, K. M. (2010) "Design and Implementation of Real Time LPRSystem on a Fixed Point DSP." 2010 6th International Conference on Emerging Technologies (ICET). IEEE, 2010. p. 159-163. doi: 10.1109/ICET.2010.5638496

[38] Wang, J. X.; Zhou, W. Z.; Xue, J. F. \& Liu, X. X. (2010) "The research and realization of vehicle license plate character segmentation and recognition technology," 2010 International Conference on Wavelet Analysis and Pattern Recognition. IEEE, 2010. p. 101-104. doi: 10.1109/ICWAPR.2010.5576426

[39] Feng, J.; Li, Y. \& Chen, M. (2010) "The Research of Vehicle License Plate Character Recognition Method Based on Artificial Neural Network," 2010 2nd International Asia Conference on Informatics in Control, Automation and Robotics (CAR 2010). IEEE, 2010. p. 317-320. doi: 10.1109/CAR.2010.5456536

[40] Anishiya, P. \& Joans, S. M. (2011) "Number Plate Recognition for Indian Cars Using Morphological Dilation and Erosion with the Aid Of Ocrs.” International Conference on Information and Network Technology. 2011.

[41] Arafat, M. Y.; Khairuddin, A. S. M. \& Paramesran, R. (2020). "Connected component analysis integrated edge based technique for automatic vehicular license plate recognition framework," IET Intelligent Transport Systems, vol. 14, no. 7, pp. 712-723, Jul. 2020, doi: 10.1049/iet-its.2019.0006.

[42] Dabholkar, R. S. \& Phakade, S. V. (2019) "Revolution by using optical character recognition technique to identify registered number plate," International Journal of Innovative Technology and Exploring Engineering, vol. 8, no. 10, pp. 1185-1188, Aug. 2019, doi: 10.35940/ijitee.I8643.0881019.

[43] Liu, Z.; Cai, Y.; Chen, L.; Wang, H. \& He, Y. (2019) "Vehicle license plate recognition method based on deep convolution network in complex road scene," Proceedings of the Institution of Mechanical Engineers, Part D: Journal of Automobile Engineering, vol. 233, no. 9, pp. 2284-2292, doi: 10.1177/0954407019851339.

[44] Gunawan, T. S.; Mutholib, A. \& Kartiwi, M. (2017) "Performance evaluation of automatic number plate recognition on android smartphone platform," International Journal of Electrical and Computer Engineering, vol. 7, no. 4, pp. 1973-1982, doi: 10.11591/ijece.v7i4.pp1973-1982.

[45] Wang, J., \& Yan, W. Q. (2016) "BP-neural network for plate number recognition,” International Journal of Digital Crime and Forensics, vol. 8, no. 3, pp. 34-45, doi: 10.4018/IJDCF.2016070103.

[46] Hidayatullah, P.; Feirizal, F.; Permana, H.; Mauluddiah, Q. \& Dwitama, A. (2016) "License plate detection and recognition for Indonesian cars," International Journal on Electrical Engineering and Informatics, vol. 8, no. 2, pp. 331-346, doi: 10.15676/ijeei.2016.8.2.7.

[47] Qu, Z.; Chang, Q. L.; Chen, C. Z. \& Lin, L. D. (2014) “An Improved Character Recognition Algorithm for License Plate Based on BP Neural Network,” The Open Electrical \& Electronic Engineering Journal, vol. 8, pp. 202-207, doi: 10.2174/1874129001408010202

[48] Pun, C. M. \& Ho, W. Y. (2011) “An Edge-Based Macao License Plate Recognition System.” International Journal of Computational Intelligence Systems, 4.2: 244-254.

[49] Hashmi, S. N.; Kumar, K.; Khandelwal, S.; Lochan, D. \& Mittal, S. (2019) "Real Time License Plate Recognition from Video Streams using Deep Learning,” International Journal of Information Retrieval Research, vol. 9, no. 1, pp. 65-87, doi: 10.4018/ijirr.2019010105. 